\title{
2
}

\section{Data and the United Nations Declaration on the Rights of Indigenous Peoples}

\author{
Megan Davis
}

\section{Introduction}

It is well understood that the existence of relevant information is a vital precondition for devising adequate policy responses to address inequalities and to monitor the effectiveness of measures to overcome discrimination, both within and between countries, as well as for identifying additional gender-based discrimination. Yet, on many occasions, the situation of indigenous peoples remains invisible within national statistics. This is especially true in many developing countries, which often have weak institutional capacities as well as limited financial resources to collect statistics and disaggregate among the various ethnic, linguistic, religious and other groups that may be present in the country. Another factor complicating data collection for indigenous peoples is that, in many countries, particularly in Africa and Asia, the formal identification and recognition of indigenous peoples is still pending, and disaggregation of data based on ethnicity may be considered, for various reasons, controversial. This chapter provides an overview of the issues pertaining to indigenous peoples and data from a United Nations (UN) perspective-in particular, 
drawing on the work of the UN Permanent Forum on Indigenous Issues (UNPFII) and the UN Declaration on the Rights of Indigenous Peoples (UNDRIP).

\section{The problem of data and indigenous peoples and the United Nations}

Data have emerged as a major concern of the UNPFII, which is a functional commission of the Economic and Social Council (ECOSOC), a body constituted by both indigenous experts and representatives of states. ${ }^{1}$ The resolution establishing the UNPFII as an advisory body to ECOSOC empowered the forum with a broad-ranging mandate to discuss indigenous issues relating to economic and social development, culture, the environment, education, health and human rights. According to the mandate, the UNPFII is expected to: 1) provide advice and recommendations on indigenous issues to ECOSOC, as well as to programs, funds and agencies of the UN through ECOSOC; 2) raise awareness and promote the integration and coordination of activities relating to indigenous issues within the UN system; and 3) prepare and disseminate information on indigenous issues. Therefore, data from UN member states and UN programs, agencies and funds are critical to the effective functioning of the forum.

A corollary to this is the unique composition of the forum. It has 16 members who are independent experts and serve for a term of three years. Eight members are indigenous and eight are state members. The indigenous members are appointed by the president of ECOSOC and represent the seven indigenous regions of the world: Africa; Asia; Central and South America and the Caribbean; the Arctic; Central and Eastern Europe, the Russian Federation, Central Asia and Transcaucasia; North America; and the Pacific. The state members are elected by ECOSOC on the basis of the five UN regional groups: Africa, Asia, Eastern Europe, Latin America and the Caribbean, and Western Europe and other states. This is a novel approach to representation in the UN but it means that the UNPFII has access to more nuanced and layered information about the composition of indigenous populations

1 Establishment of a Permanent Forum on Indigenous Issues, Economic and Social Council Resolution 2000/22, UN Doc. E/RES/2000/22 (2000). 
than it would have through UN member states, who utilise conventional ways of conveying information about indigenous peoples through official statistics that are not disaggregated.

There are two brief points to be made about the UNPFII. While the forum is seen as a major development in the international legal activism of indigenous peoples, it has also been met with some scepticism in indigenous circles. These critics argue that the UNPFII domesticates indigenous issues within Western political structures and rigid working procedures and agendas to control the dissemination of information about human rights violations against indigenous peoples and to avoid consideration of indigenous peoples' right to self-determination (see, e.g., Havemann 2001: 9; StewartHarawira 2005: 18). The second point relates to indigenous identity. Not all states acknowledge indigenous populations. During the early period of the UN's engagement with indigenous peoples, a working definition was developed in Jose Martinez Cobo's Study on the problem of discrimination against indigenous populations to traverse the politics of indigeneity:

Indigenous communities, peoples and nations are those which, having a historical continuity with pre-invasion and pre-colonial societies that developed on their territories, consider themselves distinct from other sectors of the societies now prevailing on those territories, or parts of them. They form at present non-dominant sectors of society and are determined to preserve, develop and transmit to future generations their ancestral territories, and their ethnic identity, as the basis of their continued existence as peoples, in accordance with their own cultural patterns, social institutions and legal system.

This historical continuity may consist of the continuation, for an extended period reaching into the present of one or more of the following factors:

a. Occupation of ancestral lands, or at least of part of them;

b. Common ancestry with the original occupants of these lands;

c. Culture in general, or in specific manifestations (such as religion, living under a tribal system, membership of an indigenous community, dress, means of livelihood, lifestyle, etc.);

d. Language (whether used as the only language, as mother-tongue, as the habitual means of communication at home or in the family, or as the main, preferred, habitual, general or normal language); 
e. Residence on certain parts of the country, or in certain regions of the world;

f. Other relevant factors.

On an individual basis, an indigenous person is one who belongs to these indigenous populations through self-identification as indigenous (group consciousness) and is recognized and accepted by these populations as one of its members (acceptance by the group) ... This preserves for these communities the sovereign right and power to decide who belongs to them, without external interference. (Martinez Cobo 1986-87: 379-82)

The definition of 'indigenous peoples' not infrequently is an issue for some states at the UNPFII. UNDRIP did not adopt a definition of 'indigenous peoples'; self-identification is emphasised.

In the formative days of the UNFPII, it was immediately apparent that data were the significant barrier to the work of the forum and the UN in general. For this reason, a UN expert group meeting was organised to examine the issue further. According to the Officer-inCharge of the UN Statistics Division, 'consideration of the issue of indigenous peoples and data collection was ground-breaking work'. In 2004, he identified indigenous peoples as an 'important emerging theme in social statistics'. ${ }^{2}$ From the outset, indigenous participants identified culturally specific data and standardised data to ensure that indigenous peoples were provided with data that were useful for them. In addition, the workshop report noted that participants emphasised qualitative and quantitative data combined as necessary to conceptualise indigenous peoples' issues and the underlying causes. The workshop participants argued:

Research should be carried out in partnership with indigenous peoples and the use of qualitative data in the form of case studies, reports of special rapporteurs, community testimonies, etc., would allow Governments, non-governmental organizations, indigenous organizations and the United Nations system to bring in their experience and expertise. Many experts agreed that case studies provided opportunities, which could often be extrapolated into broader lessons. Case studies allowed for the use of both qualitative and quantitative data, which provided a holistic view of the welfare of distinct peoples. ${ }^{3}$

2 Report of the Workshop on Data Collection and Disaggregation for Indigenous Peoples, United Nations Doc. E/C.19/2004/2 [11]: 10. 
On the other hand, there was caution expressed that case studies could be problematic because of the paucity of standardised data to compare with the non-indigenous population. For this reason:

[A] wide range of sources and types of data were desirable in building a complete profile of a people and also noted was the desirability of having trained indigenous peoples engaged in the full range of work concerning data collection, such as planning, collecting, analysing and report writing. ${ }^{4}$

The outcomes of the expert group meeting included the following questions relevant to data sovereignty:

- For whom are we collecting data?

- How do we collect the data?

- What should be measured?

- Who should control information?

- What are the data for?

- Why do indigenous peoples in resource-rich areas experience poor social conditions and a lack of social services?

- To what degree is remoteness responsible?

In terms of the challenges moving forward, indigenous participants identified the following obstacles and barriers:

a. Data collection was as much a political as a logistical exercise.

b. Currently available data for the most part did not adequately explain social conditions; there are gaps to be addressed.

c. Currently available data did not adequately incorporate environmental concerns.

d. Varying definitions of 'indigenous' could pose a problem in collecting data.

e. Standard forms of questions used would not always accurately reflect the situation of indigenous peoples - for example, indigenous family and social patterns were sometimes very different from the profile of the rest of the population.

f. Drifting and mobility in ethnic identity provided inconsistencies when comparing the population longitudinally. 
g. Some statistical offices pointed out the inadequate or inaccurate reporting of indigenousidentity, often as a result of misunderstanding of questions or limited opportunities to identify as belonging to more than one race or ethnicity.

h. Indigenous peoples who migrated to other countries (either voluntarily or as a result of expulsion or fleeing conflict) were often faced with the dilemma of no longer having the opportunity of identifying as indigenous in their new country. This issue was also one for the new host country and was increasingly complex because of the increasing amount of migration, both documented and undocumented.

i. The fact that indigenous peoples often resided in areas affected by war and conflicts posed an additional challenge in terms of data collection.

j. Collecting statistics on indigenous languages was useful but did not give a complete picture of the population, especially as languages were lost as a result of urbanisation, discrimination and other factors. Recording ethnic affiliation remains a problem for statisticians.

k. Lack of vital or service statistics disaggregated by ethnic group, gender and age group made it difficult to assess adequately the health situation, standard of living and coverage of health services for indigenous peoples, as well as to set priorities for action and the evaluation of impacts on these populations.

1. The challenge for public health was to translate social and cultural information into practical information to promote the welfare of indigenous communities and individuals.

$\mathrm{m}$. The economic situation of indigenous peoples was very often underrepresented in official statistics, because they often belonged to informal economies, which were reported inadequately.

n. While some data collection work and dissemination had been done in the Americas and in the circumpolar regions, in particular, limited data had been made available for Asia, Africa, the Caribbean and parts of the Pacific. ${ }^{5}$ 
It is important to stress that the expert group observed that during the meeting many of the discussions were 'intertwined' with the issue of racial discrimination. Indigenous participants were concerned that statistics, 'although seemingly neutral', could be applied for the benefit and the detriment of indigenous peoples.

The UNPFII continues to focus on the issue of data collection and has made various recommendations towards this end. In its most recent session in 2016, the forum recommended states actively engage with indigenous peoples, in both developed and developing countries, in the development of key indicators on indigenous peoples to be included in the overall indicators for the post-2015 development agenda. In addition, the UN system has made calls to states and others within the international system to collect statistics on the situation of indigenous peoples. Most recently, in the Outcome document of the World Conference on Indigenous Peoples, adopted by the UN General Assembly on 22 September 2014, member states were called on to:

commit themselves to working with indigenous peoples to disaggregate data, as appropriate, or conduct surveys and to utilizing holistic indicators of indigenous peoples' well-being to address the situation and needs of indigenous peoples and individuals, in particular older persons, women, youth, children and persons with disabilities. ${ }^{6}$

Despite these calls, to date, there have been few examples of concerted efforts to collect such data on the situation of indigenous peoples, and far fewer global efforts to collect data in a way that can allow for comparisons to be made across regions and contexts.

It is, however, worth mentioning some examples. Several countries have made progress with regard to disaggregation of data in their population, including on indigenous peoples. For example, the Government of Canada gathers statistical data on First Nation, Inuit and Métis people as part of its official census in areas such as population, education, health, employment, income and housing. These data can be compared with the statistical data collected for non-indigenous populations in the country, and generally reveal disparities in terms of social and economic outcomes. Chapters by Jelfs (this volume) and Bishop (this volume) also outline in some detail the substantial

6 Outcome document of the high-level plenary meeting of the General Assembly known as the World Conference on Indigenous Peoples, UN Doc. A/Res/69/2: para. 10. 
developments that have occurred in Australia and New Zealand. At a regional level, the Economic Commission on Latin America and the Caribbean has made efforts to 'democratise information'. With the support of a number of UN agencies, donor agencies and private funders, the commission has established a comprehensive database, which provides sociodemographic data on indigenous peoples in the region, including data disaggregated by sex and age, as well as data on internal migration, health, youth and the territorial distribution of inequalities (see ECLAC n.d.). The basis of much of this work is the inclusion by most countries in Latin America of an indigenous identifier' in their 2000 census round, thus building data through the self-identification of individuals as being a member of an indigenous community (Del Popolo, Oyarce amd Ribotta 2015). There is yet to be a genuine global effort to collect data on the situation of indigenous peoples.

\section{UNDRIP and data collection}

UNDRIP provides the common framework of the normative content of the rights of indigenous peoples and is therefore important to understanding the issues of indigenous data sovereignty. The declaration represents a global consensus regarding the rights of indigenous peoples and was adopted by the UN General Assembly, with affirmative votes by the overwhelming majority of member states, in September 2007. UNDRIP is a non-binding declaration of the General Assembly, or 'soft' international law. An aspirational document, UNDRIP provides a framework that states can adopt in their relationship with indigenous peoples and that may guide them in the development of domestic law and policy. The text creates no new rights in international law nor does it create any binding legal obligations in domestic legal systems. Many of the articles in UNDRIP are recognised in other international instruments and/or are affirmations of putative international norms as well as evolving human rights standards pertaining to indigenous peoples. ${ }^{7}$ UNDRIP is also replete with rights that are not commonly accepted as binding legal standards.

7 See, generally, Anaya (2009: 61-3); Wiessner (1999). 
UNDRIP is fundamentally a human rights instrument, and it is worth noting that there are certain difficulties in measuring human rights achievements in terms of quantitative data or statistics, given that assessing the enjoyment of human rights will always contain a strong qualitative element. Nonetheless, experiences in developing indicators to measure progress in implementing human rights in other contexts have shown that it is possible to gather statistically useful data for human rights compliance.

UNDRIP covers a range of rights, including civil and political rights, economic and social rights, and others, such as rights that are viewed as fundamental for indigenous peoples - that is, rights to lands, territories and natural resources and rights to self-determination, autonomy and participation. It can be viewed as a relatively 'complete' reflection of the substantive rights of indigenous peoples. The rights recognised in UNDRIP are deliberately grouped into several identifiable themes - the rights to: self-determination; life, integrity and security; cultural, religious, spiritual and linguistic identity; education and public information; participatory rights; lands and resources. It should be noted, however, that UNDRIP in its entirety can be read as an expression of what the right to self-determination means in practical terms for indigenous peoples.

The cluster of Articles 1-6 recognises general principles surrounding rights to nationality, self-determination, equality and freedom from adverse discrimination. This cluster includes Article 3, which affirms the indigenous right to self-determination, and Article 4, which extends this right to self-government and autonomy in relation to internal and local affairs. Articles 7-10 recognise rights to life, integrity and security. Articles 11-13 pertain to culture, spirituality and linguistic identity, including the right to practice and revitalise cultural traditions and customs as well as the right to maintain, protect and develop past, present and future manifestations of indigenous culture.

Articles 14-17 deal with indigenous rights to education, information and labour rights, including the right of all children to education by the state as well as the right to establish and control indigenous educational systems and institutions. Articles 18-23 are participatory rights that enable special measures for immediate, effective and continuing improvement of indigenous economic and social conditions 
in the areas of employment, vocational training and retraining, housing, sanitation, health and social security. This section also provides that states shall take measures to ensure that indigenous women and children enjoy the full protection and guarantees against all forms of violence and discrimination.

Articles 24-31 deal with lands, territories and resources. Indigenous peoples have the right to own, develop, control and use the lands and territories they have traditionally owned or otherwise occupied or used. This includes the right to the full recognition of their laws, traditions and customs, land-tenure systems and institutions for the development and management of resources, and the right to effective measures by states to prevent any interference with, alienation of or encroachment on these rights. Articles 32-36 explain how the right to self-determination can be implemented, including matters relating to internal local affairs such as culture, education, information, media, housing, employment, social welfare, economic activities, land and resources and the environment. This section empowers indigenous peoples with the right to determine citizenship in accordance with customs and tradition. Most notably, it empowers indigenous peoples to promote and maintain traditional judicial customs, procedures and practices.

UNDRIP also gives guidance to states on how these substantive rights can be implemented within domestic legal and political systems. Article 37 recognises the right of indigenous peoples to conclude treaties, agreements or other constructive arrangements with states. Article 38 provides that the state, in cooperation with indigenous peoples, shall take appropriate measures including legislative measures to achieve the ends of UNDRIP; and Article 39 states that indigenous peoples have the right of access to financial and technical assistance from states for the enjoyment of the rights recognised in UNDRIP. Articles 40-46 are implementation provisions expounding the role of the state and international organisations in recognising the rights provided in UNDRIP. Article 46 of the declaration renders all the articles subject to existing international and domestic law. This means that the rights are relative and must be balanced with the rights of others. 
The most important rights underpinning the framework of UNDRIP are the two key provisions on the right to self-determination:

\section{Article 3}

Indigenous peoples have the right of self-determination. By virtue of that right they freely determine their political status and freely pursue their economic, social and cultural development.

\section{Article 4}

Indigenous peoples, in exercising their right to self-determination, have the right to autonomy or self-government in matters relating to their internal and local affairs, as well as ways and means for financing their autonomous functions.

UNDRIP was developed with the active participation of indigenous peoples themselves, and reflects indigenous peoples' own priorities, views and concepts of wellbeing and culturally appropriate development. In this context, UNDRIP's affirmation of universal human rights standards that apply to indigenous peoples across the world, and that have been supported by states and indigenous peoples across the world, addresses an important element of data collection: the existence of universally acceptable standards for measurement to allow for cross-country comparison.

Measuring implementation of the human rights standards affirmed in UNDRIP will require the collection of both objective and subjective data (also referred to as 'fact-based' and 'judgment-based' data). These elements are complementary and mutually reinforcing, and both present important opportunities for the collection of data spearheaded by indigenous peoples themselves.

With respect to objective data, relevant information will include the existence of laws, policies and programs, as well as concrete actions, in line with the provisions of UNDRIP - for example, the existence of constitutional recognition of indigenous peoples, the total of lands demarcated in favour of indigenous peoples, the number of indigenous students with access to bilingual education programs, and so on. Collecting such data can often be conducted through a 'desk review' or through a review of available administrative data collected by the state or other sources. However, collection of such data by indigenous peoples themselves will also be essential, especially in countries with 
limited technical and financial capacities, or political will, to gather such information, and overcoming this constraint remains one of the major challenges for the UNPFII and allied agencies.

For its part, subjective data will measure, generally through the use of a survey or questionnaire, to what extent indigenous peoples perceive that their rights are being implemented-for example, whether their views have been reflected in a development plan and the perceived security of tenure of the lands and resources under traditional ownership. Collecting subjective data presents additional challenges in terms of resources and maintaining consistent data collection, but it also presents important opportunities for indigenousdriven efforts and for ensuring that indigenous peoples' rights and priorities are reflected in the data collected.

A first step in collection of data on the situation of indigenous peoples will be the development of appropriate indicators and surveys based on UNDRIP that can be applied in local contexts around the world. A second step is to train indigenous peoples, but also states, nongovernmental organisations (NGOs) and others, in the collection of such data and to provide them with the tools necessary to do so. Finally, it is necessary that some entity at the global or regional levelperhaps within the UN-compiles, analyses and publishes the data.

A very interesting emerging example is the 'Indigenous Navigator' project being developed by a collection of UN organisations and NGOs, including the International Work Group for Indigenous Affairs, the Asia Indigenous Peoples Pact, the Forest Peoples Programme, the International Labour Organization (ILO) and the Tebtebba Foundation. The project has developed a framework and set of tools and indicators for indigenous peoples themselves to systematically monitor the level of recognition and implementation of their rights. The project uses as a basis for measurement the rights affirmed in UNDRIP and has devised a set of indicators that relate to clusters of rights covered by UNDRIP, including lands and resources, languages, self-government, participation, consultation and consent and recognition of identity. The project is now in a pilot phase and no doubt the information that emerges from the data collection process will be highly useful in various other contexts. 


\section{Conclusion}

As part of its future work, the UNPFII has discussed the formulation of an indigenous peoples' index, based on the human rights affirmed in UNDRIP. At its annual session in 2015, the UNPFII held a panel discussion on this issue. It concluded that in establishing indicators, the focus should be on the vision and world views of indigenous peoples, based on collective rights, such as those to identity, land, territories and resources, free, prior and informed consent and indigenous women's participation in local, national and international decision-making processes. The forum will continue this work, building on positive experiences that already exist around the world, and it hopes to draw on the support of UN agencies, national statistics offices, academics and others, including and especially indigenous peoples themselves, to collaborate in this effort.

\section{References}

Anaya SJ (2009). International human rights and indigenous peoples, Aspen Publishers, New York.

Del Popolo F, Oyarce AM and Ribotta B (2015). Sistema de Indicadores Sociodemográfico de Poblaciones y Pueblos Indígena de América Latina-SISPPI. Guia para el usuario [System of sociodemographic and population indicators and indigenous peoples of Latin AmericaSISPPI. User guide], Santiago: CELADE/CEPAL-Fondo Indígena, celade.cepal.org/redatam/PRYESP/SISPPI/SISPPI_notastecnicas.pdf.

Economic Commission for Latin America and the Caribbean (ECLAC) (n.d.). Indigenous peoples and Afro-descendants in Latin America and the Caribbean data bank-PIAALC, ECLAC, Port of Spain, www.cepal.org/en/indigenous-peoples-and-afro-descendantslatin-america-and-carribean-data-bank-piaalc.

Havemann PL (2001). The participation deficit: globalization, governance and indigenous peoples. Balayi: Culture, Law and Colonialism - Indigenous Peoples in the International Sphere 3:9-36. 
INDIGENOUS DATA SOVEREIGNTY

Martinez Cobo J (1986-87). Study of the problem of discrimination against indigenous populations, UN Doc. E/CN.4/Sub.2/1986/7, United Nations, New York, www.un.org/development/desa/ indigenouspeoples/publications/2014/09/martinez-cobo-study/ \#more-7242.

Stewart-Harawira M (2005). The new imperial order: indigenous responses to globalization, Zed Books, London.

Wiessner S (1999). Rights and status of indigenous peoples: a global comparative and international legal analysis. Harvard Human Rights Journal 12:57. 
This text is taken from Indigenous Data Sovereignty: Toward an agenda, edited by Tahu Kukutai and John Taylor, published 2016 by ANU Press, The Australian National University, Canberra, Australia. 